\title{
Recomendaciones y propuestas de mejora para los destinos culturales de carácter rural: El caso de estudio de la Villa del Libro de Urueña (Valladolid)
}

\author{
Alberto Azuara Grande* Javier De Esteban Curiel*** \\ Isabel Del Río de la Hoz*** \\ Universidad Rey Juan Carlos (España)
}

\begin{abstract}
Resumen: El turismo literario se ha caracterizado por ser una tipología de turismo cultural relativamente reciente en España y consolidada en distintos países europeos, que ha avanzado en importancia e independencia hasta el punto de especializarse en ello destinos enteros, en muchas ocasiones ligados al mundo rural. Las iniciativas Villa del Libro han venido a desarrollarse como una variante de este turismo literario, a partir de la proliferación de librerías en pequeñas localidades que sirven como núcleo de desarrollo de todo su entorno. El presente artículo se ha constituido a partir de una investigación cualitativa mediante la realización de entrevistas en profundidad a dos expertos en turismo cultural. De su posterior análisis se han extraído y determinado las estrategias necesarias para el éxito y consolidación de los destinos culturales de carácter rural y el de la propia Villa del Libro de Urueña (Valladolid) como destino cultural de referencia en España.
\end{abstract}

Palabras Clave: Turismo literario; turismo cultural; destinos rurales; Villa del Libro; dinamización; análisis cualitativo.

Recommendations and proposals for improvement in rural cultural destinations: The case study of the Book Town of Urueña (Valladolid, Spain)

Abstract: Literary tourism is a specific form of cultural tourism that is relatively recent in Spain and widely consolidated in different European countries, where it has grown in importance to the point of whole destinations being built around the same, often in rural landscapes. Book Town initiatives have been positioned as a variation of literary tourism and consists in a plethora of bookshops in small towns that serve as the nucleus for regional economic and social development. This paper offers qualitative research on the subject, the result of in-depth interviews with two experts in cultural tourism. From the subsequent analysis, it is clear that management and marketing strategies are essential, among other aspects, for the success and consolidation of rural cultural destinations. The analysis centres most specifically on the Book Town of Urueña (Valladolid) as the Spanish reference for this type of tourism.

Keywords: Literary tourism; Cultural tourism; Rural destinations; Book Town; Local development; Qualitative analysis.

\section{Introducción}

La consolidación de nuevas tipologías de destinos turísticos culturales ha sido una constante en las últimas décadas, dadas las múltiples posibilidades que han sido capaces de ofrecer las ciudades y otros espacios para el atraimiento de los turistas, y el apoyo de las administraciones para efectuar los

URJC - Escuela Internacional de Doctorado, Programa de Doctorado Interuniversitario en Turismo; E-mail: albertoagrande@ gmail.com

* URJC - Profesor Titular de Universidad. Dpto. Economía de la Empresa; E- mail: javier.deesteban@urjc.es

*** URJC - Profesora Titular de Universidad. Dpto de Ciencias de la Educación, Lenguaje, Cultura y Artes, Ciencias Histórica-Jurídicas y Humanísticas y Lenguas Modernas. Área de Historia del Arte; E-mail: isabel.delrio@urjc.es 
desarrollos correspondientes. Asimismo, el incremento de la demanda de turistas que, con motivaciones diferentes, acaban visitando estos destinos culturales, ha significado también el aumento de la variedad de la oferta disponible, adaptándose a los distintos tipos de turistas existentes. Bajo este marco, el turismo literario ha sido una de estas tipologías turísticas que han conseguido poner en valor de cara al turismo los recursos vinculados al mundo del libro, generalmente relacionados con obras literarias, autores y sus vidas, o bien personajes y escenarios ficticios, y por tanto, configurar en torno a estos atractivos literarios un espacio turístico con la infraestructura necesaria para ello.

Como forma de recuperación y revitalización de áreas rurales en declive, surgió en Europa una iniciativa derivada del turismo literario denominada Villas del Libro, que pretendía hacer de estas poblaciones centros vinculados a la compraventa de libros que con el paso del tiempo, han derivado en auténticos destinos turísticos especializados en el mundo del libro, a los que se les han ido añadiendo otras actividades complementarias. Estos desarrollos turísticos en forma de Villas del Libro presentan particularidades propias que hacen que puedan dificultar su clasificación como destinos de turismo literario propiamente dichos, puesto que buena parte de ellos no disponen de conexiones directas con autores u obras literarias que se hayan desarrollado en los mismos. Pese a ello, su clara vinculación con la literatura a través de las actividades mencionadas configura dicha relación con el mundo del libro y con los expertos e interesados en esta materia, que pueden trasladarse hacia estos destinos atraídos por su singularidad.

Así pues, el objetivo principal de esta investigación ha sido tratar de constatar la idoneidad del turismo de Villas del Libro de cara al futuro dadas sus especiales particularidades, vinculadas a su especificidad y a su carácter internacional, así como las potencialidades que pueden surgir de ellas. Para ello, se ha tomado como caso de estudio la localidad de Urueña, única Villa del Libro reconocida como tal en España desde 2007, sirviendo de referencia para el análisis cualitativo realizado sobre el contenido de las entrevistas en profundidad realizadas a los expertos, manifestando una serie de conclusiones y recomendaciones específicas para estos destinos.

\section{Revisión de literatura}

\subsection{El turismo cultural}

El estudio del turismo cultural ha sido una constante durante las últimas décadas entre los investigadores turísticos, dando lugar a diferentes definiciones sobre este fenómeno, tanto desde un punto de vista más técnico como desde otro más genérico o conceptual (OMT, 1985; Richards, 1996), así como una amplia variedad de clasificaciones de tipologías y actividades puede agrupar (ECTARC, 1989 en Richards, 1996; Swarbrooke, 1996; Smith, 2003, pp. 36-37; Recuero et al., 2016). De este modo, Richards (2001) considera que la principal diferencia entre el turismo cultural y otros tipos de turismo se resume básicamente en la función de aprendizaje que toman los turistas durante su estancia en el destino. Así, Richards (2001) se enfoca en comprender la cultura a partir de su composición a partir de una serie de procesos mentales, y los productos de esos procesos. En este sentido, el turismo cultural no se trataría solamente de visitar espacios históricos y monumentales, que ha sido la forma habitual de entender este tipo de turismo, sino también de sumergirse en la cultura local y formas de vida de los lugares que se visitan.

Igualmente, Richards (2001) asegura que el turismo cultural, al margen del consumo de productos turísticos relacionados con el legado histórico y patrimonial de tiempos pasados, también se enmarca en el consumo de la cultura contemporánea de los lugares visitados. Por su parte, Garrod y Fyall (2000) consideran que los elementos imprescindibles que debe poseer el turismo cultural son: prioridad a la conservación y salvaguarda del patrimonio, accesibilidad para toda la sociedad, poseer un carácter educativo, tener relevancia ante el mayor público posible, finalidad de recreo y entretenimiento, revertir los ingresos obtenidos a través del turismo en el propio beneficio del patrimonio, y buscar la total armonía con las comunidades locales.

\subsection{El turismo literario como modalidad de turismo cultural}

Las clasificaciones mencionadas en el subepígrafe anterior, mostraban que las actividades turísticas vinculadas a la literatura pueden llegar a convertirse en un verdadero producto de turismo cultural tras afrontar un proceso de comodificación de los recursos existentes (Cohen, 1988; McKercher y Du Cros, 2002, pp.124-127; Vera, et al. 2011, pp.87-88; Recuero et al. 2016, pp.103-104). De esta forma, autores como Butler (2002) o Magadán y Rivas (2010) definen al turismo literario como una modalidad turística 
vinculada a la visita de lugares relacionados de una forma u otra con la literatura, ya sea a través de los propios autores y sus vidas, sus obras o sus personajes y acontecimientos reales o imaginarios.

Autores como Squire (1994), Herbert (1996, 2001), McKercher y Du Cros (2002), o Robinson y Andersen (2003) consideran que el turismo literario es una buena forma de estimular el desarrollo económico para aquellas comunidades locales que deseen poner en valor los recursos literarios con los que cuentan. Igualmente, Squire $(1994,1996)$ y Robinson y Andersen (2003) exponen que el turismo literario es una potente herramienta que aporta a los visitantes y a la sociedad en general unas determinadas experiencias turísticas basadas en lo literario, además de comunicar una serie de valores, ideas y significados culturales. Por otro lado, estos mismos autores aseguran que la aparición y mantenimiento de dicha tipología de turismo cultural se debe a la existencia de una demanda constante de turistas que están dispuestos a consumir las experiencias ofrecidas en los destinos literarios. Squire (1996) añade que el turismo literario, al igual que todo turismo cultural, se estructura en torno al deseo del público de experimentar una versión del pasado y a las conexiones entre la realidad y la ficción, mostrándose de acuerdo con los enunciados de Cohen (1988) y McCannell (1999), en los que consideran que los turistas buscan la diferenciación fuera de su entorno, y en el caso del turismo cultural en general, una forma de volver a una época pasada y ajena a las formas de vida actuales.

En referencia a la satisfacción de los turistas literarios, Robinson y Andersen (2003) consideran que el turismo literario permite introducir a los turistas en distintos elementos contenidos en la vida y obra de los escritores, así como en los diferentes aspectos del mundo literario en general, por lo que posee cualidades suficientes como para que los turistas obtengan una experiencia turística satisfactoria.

Sin embargo, Robinson y Andersen (2003, pp.14-15) consideran que los procesos de comodificación llevados a cabo en los destinos culturales pueden desembocar en pérdidas de autenticidad en los recursos, así como una inadecuada interpretación y presentación de los mismos. A pesar de todo, creen que en un mundo literario principalmente imaginado e irreal, dicha autenticidad de los lugares turísticos literarios puede resultar más difícil de reconocer. Así, Robinson (2003, p.52) añade que al ser el turismo literario una experiencia subjetiva para cada turista, la supuesta objetividad de la autenticidad no tendría así sentido. De forma similar, Fawcett y Cormack (2001, p.700) consideran que al mismo tiempo que los propios turistas pueden interpretar de forma múltiple y contradictoria los sitios, son los propios gestores de estos sitios literarios los que deben controlar esta situación. Según Herbert (2001, pp.317-318), el hecho de que los lugares literarios cuenten con elementos tanto del mundo real como del imaginario es el causante de que aparezca el debate sobre la autenticidad de éstos y la forma en la que deben ser presentados hacia los turistas.

\subsection{Las Villas del Libro. Origen y desarrollo}

Para conocer las primeras investigaciones turísticas sobre estos destinos, es necesario comenzar por el momento en el que Seaton (1996a, 1996b) publica los resultados de su investigación acerca del origen y desarrollo en la década de 1960 de la primera Villa del Libro, Hay-on-Wye. Esta pequeña localidad galesa fue pionera en convertir antiguas propiedades en librerías de segunda mano, a partir de una iniciativa privada desarrollada por el controvertido librero Richard Booth, dotando a la población de un resurgir en un medio rural en declive, gracias al comercio de libros, a la celebración de un festival literario hoy conocido a nivel internacional, el Hay Festival, y al consiguiente desarrollo del conglomerado turístico.

Según Seaton (1996a, 1996b), el estudio realizado sobre Hay-on-Wye desveló que el desarrollo turístico en forma de Villa del Libro, resulta ser "un modelo ejemplar de turismo rural sostenible", ya que se reconvierten recursos ya existentes para favorecer el desarrollo económico, las transformaciones acontecidas no perjudican el medio ambiente ni el Patrimonio Cultural, los beneficios generados por la actividad turística permanecen en la población local, se crean nuevos empleos a través de la compra-venta de libros usados, se generan nuevos servicios turísticos adscritos al mero hecho literario, se sitúa a la Villa del Libro como centro del turismo de una región o comarca, es un turismo menos estacional, y es capaz de generar una cantidad importante de turismo internacional, así como un turismo de calidad y de alto poder adquisitivo.

Respecto al perfil del turista que visita Hay-on-Wye y que puede extrapolarse al resto de Villas del Libro, Seaton (1996b) lo determina como mayoritariamente hombres, de entre 31 y 40 años, con estudios superiores y elevado poder adquisitivo, destacando profesionales de la medicina, la educación o directivos, procedentes de zonas alejadas del entorno del destino y que no pernoctan, con la intención de realizar un importante gasto en la compra de libros, por lo que el autor considera que el turismo de Villas del Libro es practicado por "turistas de calidad". 
Seaton (1996c, 1999) también expuso los resultados acerca del estudio sobre el resto de localidades europeas que desde 1985 emprendieron esta iniciativa, así como el caso de la localidad escocesa seleccionada para tal fin. Respecto a estas Villas del Libro, el autor las considera como seguidoras del modelo implantado por Hay-on-Wye, a pesar de ser promovidas en buena parte por el sector público y de contar con un éxito más reducido que la primera. Estas Villas del Libro serían Becherel y Montolieu en Francia, Redu en Bélgica, Bredevoort en los Países Bajos, y Waldstadt-Wunsdorf en Alemania. Igualmente, Seaton (1999) expone los pasos seguidos para implantar la iniciativa literaria en Escocia, seleccionándose la localidad de Wigtown dadas sus condiciones similares a las Villas del Libro ya implantadas, y sustentada a través de un consorcio público-privado de agentes, siendo la primea de ellas en contar con esta estructura de gestión mixta.

Durante los primeros años del siglo XXI, la proliferación de destinos Villa del Libro fue constante en diferentes países europeos, llegándose incluso a crear en 2000 la Organización Internacional de Villas del Libro. Sin embargo, este crecimiento en importancia de estos destinos no ha ido acompañado de nuevas investigaciones turísticas, salvo un informe (McShane, 2002) en el que se ponen de manifiesto diferentes elementos sobre las Villas del Libro existentes por aquel entonces.

\subsection{Caso de estudio: La Villa del Libro de Urueña}

Por lo que respecta al caso de estudio que nos ocupa en esta investigación, en Urueña (Valladolid), convertida desde 2007 en la primera Villa del Libro de España, tampoco han existido demasiadas investigaciones turísticas sobre este destino turístico, al margen de una investigación empírica (Bedate et al., 2001) que consistió principalmente en detectar los perfiles y características de los visitantes culturales de Castilla y León, realizándose dicha investigación sobre un museo, un conjunto histórico-artístico amurallado (la Villa de Urueña), una catedral y un festival de música; y otra investigación en forma de Trabajo Fin de Grado (Reguera, 2014) acerca de la imagen de destino de Urueña. De esta forma, gracias a las publicaciones del principal ideólogo del proyecto Urueña, Villa del Libro (Manrique, 2006a, 2006b) es posible conocer la forma en que fue desarrollado, cuyas características principales residen en la inspiración sobre el resto de Villas del Libro de Europa, el apoyo eminentemente público por parte de la Diputación de Valladolid, y el objetivo de servir de centro neurálgico de la dinamización comarcal, foco de atracción de la cultura y de encuentro de profesionales e interesados en ella.

Tras la realización de un intensivo trabajo de campo y de observación directa sobre el destino, es posible describir la situación en la que se encuentra. Actualmente, la Villa de Urueña cuenta con 207 habitantes según el Censo de 2011 elaborado por el INE, y dispone de oferta turística principal de 13 librerías y talleres, 4 alojamientos rurales, y 5 establecimientos de restauración. En cuanto a la oferta museística y cultural, la villa cuenta con un centro etnográfico de prestigio internacional (Fundación Joaquín Díaz); el Centro E-LEA, dependiente de la Diputación de Valladolid y sede de la Villa del Libro; el Museo del Cuento; el Museo de la Música Luis Delgado; el Museo de Campanas Quintana; y la sala de exposiciones temporales Espacio DiLab. Asimismo, Urueña cuenta con 2 establecimientos de artesanía y antigüedades, 4 establecimientos de alimentación y productos locales, y una Oficina de Turismo dependiente del Ayuntamiento. También debe indicarse que el destino forma parte de la Asociación de pueblos más bonitos de España y de la Organización Internacional de Villas del Libro.

Respecto a su oferta de Patrimonio Cultural, la Villa del Libro cuenta con un castillo y murallas medievales, la renacentista iglesia de Sta. $\mathrm{M}^{\mathrm{a}}$ del Azogue, la ermita románica dedicada a la Virgen de la Anunciada, así como varias edificaciones civiles monumentales de los siglos XV, XVI y XVIII, entre otros elementos de interés. La villa se encuentra declarada Conjunto Histórico-Artístico.

A modo de descripción sobre la demanda turística, destacar que las estadísticas de la Oficina de Turismo de Urueña recogieron en el año 2016 un total de 16.934 personas que consultaron información en la misma, existiendo un aumento respecto al año 2015, en el que se registraron 15.938 personas. A pesar de ello, el aumento más significativo se produce respecto al 2014, que contó con 9317 personas registradas. Igualmente, desde la Fundación Joaquín Díaz también se ofrece un registro de visitantes de su museo, que vendió en 2016 un total de 7412 entradas, así como del Museo de Campanas, que registró 4637 visitantes en este mismo año.

Por otro lado, gracias a la investigación de Bedate et al. (2001), es posible conocer el perfil del turista que visitaba Urueña antes de su declaración como Villa del Libro. En este sentido, los autores afirmaban que el perfil del turista de la localidad eran mayoritariamente hombres, de entre 21 y 50 años, con estudios superiores e ingresos elevados, con profesiones relacionadas con la cultura, la arquitectura y la ingeniería, y procedentes en su mayoría del entorno de Valladolid, los cuales ya entonces compraban 
en el destino mayoritariamente libros y otros productos locales. Por tanto este estudio desvela que no existen grandes diferencias entre el perfil del turista que planteaba Seaton (1996b) y el encontrado en Urueña antes de su declaración en 2007.

En cuanto a las comunicaciones que posee el destino, destacar su situación privilegiada junto a la autovía A-6, que le proporciona acceso directo desde Madrid (225 km), así como su proximidad a grandes núcleos de población como Valladolid, Tordesillas o Medina de Rioseco. Asimismo, Urueña se sitúa muy próxima por carretera a otros enclaves de interés turístico como el Monasterio de la Santa Espina, San Cebrián de Mazote o Tiedra, entre otras poblaciones de la comarca de los Montes Torozos. En materia de transporte público, Urueña cuenta con un servicio de autobuses públicos que lo conecta con Valladolid y otras localidades. Como añadido, a la entrada de la localidad existe suficiente espacio de aparcamiento tanto para automóviles como para autocares.

Respecto a la señalización del destino, Urueña cuenta con indicaciones de carretera en su entorno suficientes para guiar a los turistas, así como señalización turística de a pie en el interior de su casco urbano, estando referenciados todos los establecimientos de oferta turística y cultural, así como todos los recursos culturales existentes.

En cuanto a la información turística, tanto en la Oficina de Turismo como en el Centro E-LEA existe personal capacitado para proporcionar a los turistas la información necesaria a través de publicaciones editadas por diferentes administraciones y entidades culturales presentes en el destino. Por su parte, las dos principales páginas web oficiales para informarse sobre el destino son la web de Turismo de la Provincia de Valladolid y la web municipal del Ayuntamiento de Urueña.

\section{Metodología}

Esta investigación se desarrolla a grandes rasgos mediante el empleo del análisis cualitativo a través de la técnica de las entrevistas en profundidad semiestructuradas para la recogida de información. En este sentido, el análisis de los datos cualitativos obtenidos a través de las entrevistas, es realizado a través del método del Análisis de Contenidos.

\subsection{La investigación en turismo y el análisis cualitativo}

Veal (2006, pp.2-3) define la investigación científica como aquel tipo de investigación guiada a través del seguimiento de unas normas y pautas concretas, siempre basándose en aspectos lógicos y razonables, así como en la comprobación de la existencia de evidencia científica. En el caso de las ciencias sociales, entre ellas el turismo, el autor expone la necesidad de adaptar los métodos de investigación científica a las particularidades de dicho conocimiento, esto es, al tratamiento directo con las personas y la consecuente dificultad para predecir sus comportamientos.

En la investigación turística, al igual que en el resto de ciencias sociales, es posible realizar investigaciones a partir de datos cuantitativos y también cualitativos, dando lugar a dos formas de analizar la información en función de las características de los datos. De esta forma, y tratándose en este caso de una investigación realizada a partir de datos cualitativos, corresponde definir dicho análisis. De esta forma, Veal (2006, p.40) define el análisis cualitativo como "aquel que implica reunir un gran cantidad de información sobre un grupo reducido de personas", en donde "la información recogida no es presentada generalmente en forma numérica". El autor matiza que en el caso del turismo, este análisis suele ser el empleado cuando se requiere presentar las afirmaciones de unos pocos expertos en la materia. Por su parte, Sancho (2001, p.12) considera que "la investigación cualitativa es una estrategia usada para responder a preguntas sobre los grupos, comunidades e iteraciones humanas y tiene una finalidad descriptiva de los fenómenos de interés o predictiva de los fenómenos turísticos, o de los comportamientos humanos y su relación con el turismo."

\subsection{La entrevista en profundidad como técnica de recogida de datos}

Babbie (2000, p.268) y Hernández Sampieri et al. (2007, pp.221-222) definen la entrevista como una "conversación" en la que generalmente participan dos personas, un entrevistador que aporta las directrices básicas y las preguntas necesarias para asegurar un buen desarrollo de la entrevista, y un entrevistado o experto que se limita a responder dichas preguntas en función de sus conocimientos. Ambos autores destacan la flexibilidad de la que éstas disponen, en el sentido de que existe la posibilidad de efectuar guiones semiestructurados que cuenten con determinadas preguntas principales y al mismo tiempo 
se permita orientar la conversación en función de los requerimientos de la misma y de las necesidades del entrevistador. Por su parte, Veal (2006, pp.198-199) considera que el elemento de distinción de la entrevista en profundidad frente a otras técnicas cualitativas es el empleo de dicho guión abierto, el cual podrá seguirse a consideración del entrevistador mientras se traten todos los temas previstos en el mismo. Los tres autores coinciden en la necesidad de tomar notas y grabar el contenido de la entrevista, a fin de poder analizarla adecuadamente y con mayor facilidad. Investigaciones recientes sobre turismo cultural basadas en el empleo de metodología cualitativa a través de entrevistas en profundidad, como las realizadas por Prat y Cànoves (2016) sobre el turismo judío en España, reflejan que es una forma más de ampliar el conocimiento sobre estas tipologías turísticas.

\subsection{El Análisis de Contenidos}

El Análisis de Contenidos, según López Noguero (2002), puede determinarse como un mecanismo empleado para desgranar el contenido de un documento concreto, atendiendo al significado en conjunto del mismo, sus argumentaciones y lo que pretende transmitir. Por tanto, a través del Análisis de Contenidos se trataría más de verificar lo que trata de decir el texto, y no tanto cómo está escrito, tratando de eliminar la subjetividad de interpretación de un texto. De esta forma, el autor argumenta que para llevar a cabo un Análisis de Contenidos, es necesario seguir una serie de procedimientos con el objetivo de cuantificar y medir el contenido de los textos, lo que se traduce en diferenciar los contenidos según campos de estudio, conceptos e ideas, o definiciones. En este sentido, Hernández Sampieri et al. (2007, pp.289-305) describen los seis pasos que deben seguirse para realizar un análisis cualitativo de los contenidos de una entrevista en profundidad o cualquier otra técnica, siendo éstos: 1 . Revisar el material, 2. Codificar o categorizar los datos, 3. Interpretar los datos, 4. Describir contextos y explicar sucesos, 5. Verificar la calidad de la información, y 6. Corregir y ajustar. Por su parte, Babbie (2000, pp.286-296) plantea un enfoque similar para la realización de un análisis de contenidos, destacando como ventajas del mismo la accesibilidad para todo aquel que desee realizarlo, la facilidad de rectificación en el análisis, o el escaso efecto que el analista tiene sobre el objeto estudiado.

En el caso del empleo del Análisis de Contenidos en las investigaciones turísticas, destacar el estudio de Camprubí y Coromina (2016), en el cual los autores detectan que desde 1986 a 2012 se han publicado 164 artículos en revistas científicas de alto impacto vinculadas al turismo que emplean el análisis de contenidos en su investigación, existiendo en esta franja temporal un incremento exponencial en el número de artículos de este tipo publicados, lo que demuestra la cada vez mayor importancia de este tipo de análisis cualitativo en la investigación turística.

Tabla 3.1: Ficha técnica de resumen.

\begin{tabular}{|l|c|c|c|}
\hline \multicolumn{2}{|c|}{ Ficha técnica } & \\
\hline Tipo de entrevista & $\begin{array}{c}\text { Entrevista E1 } \\
\text { guión semiestructurado }\end{array}$ & $\begin{array}{c}\text { Entrevista E2 } \\
\text { guión semiestructurado }\end{array}$ & $\begin{array}{c}\text { Entrevista E3 } \\
\text { guión semiestructurado }\end{array}$ \\
\hline Fecha de realización & 14 de abril de 2016 & 6 de octubre de 2016 & $\begin{array}{c}\text { Técnico gestor en la } \\
\text { Villa del Libro }\end{array}$ \\
\hline Duración & 30 minutos & 35 minutos & 1 de octubre de 2016 \\
\hline Lugar & Cafetería en Alcobendas \\
(Madrid) & A través de Skype & 62 minutos \\
\hline Técnica de análisis & Análisis de Contenidos & Análisis de Contenidos & Urueña (Valladolid) \\
\hline Software de análisis & Atlas.ti & Atlas.ti & Análisis de Contenidos \\
\hline Software de análisis & Atlas.ti 8.0 & Atlas.ti 8.0 & Atlas.ti 8.0 \\
\hline
\end{tabular}

Fuente: elaboración propia. 


\subsection{La entrevista aplicada al estudio en concreto}

Como se ha mencionado al principio de este apartado, para este estudio cualitativo se han realizado dos entrevistas en profundidad a expertos en turismo cultural con un guión semiestructurado similar para ambas entrevistas, a fin de poder realizar comparaciones válidas en el análisis de las mismas. Las preguntas de dicho guión fueron elaboradas y respaldadas a partir del constructo bibliográfico consultado para esta investigación. En este sentido, respecto a las entrevistas realizadas a ambos expertos (E1 y E2), tuvieron una duración aproximada de 30 minutos, y ambas fueron debidamente grabadas y posteriormente transcritas para su análisis posterior mediante el software Atlas.ti. Así pues, el E1 es investigador en marketing del turismo cultural en la Universidad Complutense de Madrid, mientras que el E2 es director de una importante plataforma digital de investigación sobre diferentes aspectos del sector cultural y su vinculación con las nuevas tecnologías.

\subsection{Limitaciones de la investigación}

La principal limitación que se ha presentado al realizar esta investigación cualitativa se vincula con la realización de dos entrevistas en profundidad a expertos en turismo cultural, dado que resultó francamente complicado encontrar personas experimentadas en el campo más específico de los destinos literarios y que conocieran el caso de las Villas del Libro. Sin embargo, desde esta investigación se pretende hacer frente a esta limitación iniciando nuevas líneas de investigación en este campo, con el objetivo de otorgar una mayor difusión a esta tipología turística y a su conocimiento por parte de los investigadores en turismo cultural.

\section{Resultados}

Tras la realización del análisis de las entrevistas en profundidad y su debida interpretación, se presentan los principales resultados obtenidos en ambas entrevistas.

Tabla 4.1: Resumen de resultados sobre la entrevista al experto E1.

\begin{tabular}{|l|l|}
\hline \multicolumn{2}{|c|}{ Entrevista E1 } \\
\hline Palabras clave detectadas & $\begin{array}{l}\text { Comodificación, profesionalización, } \\
\text { satisfacción de los visitantes, experiencias, } \\
\text { nuevas tecnologías, sostenibilidad, } \\
\text { población local, destino ampliado. }\end{array}$ \\
\hline Palabras indígenas & $\begin{array}{l}\text { Co-creación, customer journey, "Diez P del } \\
\text { marketing", lealtad del turista, asociación } \\
\text { de destinos. }\end{array}$ \\
\hline Palabras más repetidas & $\begin{array}{l}\text { Comportamiento del turista cultural: } \\
\text { visitar (16), experiencia (12), necesidad } \\
\text { (11), motivación (7). }\end{array}$ \\
$\begin{array}{l}\text { Gestión Turismo Cultural: cultura (34), } \\
\text { destino (28), gestión (14), red (18), } \\
\text { desarrollo (7), acuerdo (7), asociación (7), } \\
\text { conocimientos (6). } \\
\text { Marketing turístico: marketing (14), } \\
\text { nuevas tecnologías (8), volver (6) } \\
\text { promoción (6), producto (4). }\end{array}$ \\
$\begin{array}{l}\text { Sostenibilidad: } \text { sostenibilidad } \\
\text { (8), concienciación (6), social (8), } \\
\text { masificación (6), impactos (4), } \\
\text { presupuestos (4). }\end{array}$ \\
\hline
\end{tabular}

Fuente: elaboración propia. 
Tabla 4.2: Resumen de resultados de la entrevista al experto E2.

\begin{tabular}{|l|l|}
\hline \multicolumn{2}{|c|}{ Entrevista E2 } \\
\hline Palabras clave detectadas & $\begin{array}{l}\text { Nuevas tecnologías, turismo cultural, } \\
\text { diversificación, especialización, } \\
\text { profesionalización, boca-oreja, } \\
\text { internacionalización. }\end{array}$ \\
\hline Palabras indígenas/Nuevos conceptos & Product placement \\
\hline Palabras más repetidas & $\begin{array}{l}\text { Gestión del turismo cultural: Económico (10), } \\
\text { entidades (8), gestión (8), trabajo (7), oferta } \\
\text { (7), entorno (6), desarrollo (5), destino (5), } \\
\text { profesional (5). } \\
\text { Nuevas tecnologías: Internet (13), página web } \\
\text { (5), redes sociales (3). }\end{array}$ \\
& $\begin{array}{l}\text { Estrategias de marketing: Marca (13), } \\
\text { diferenciación (9), promoción (8), } \\
\text { especialización (7), boca-oreja (6). }\end{array}$ \\
\hline
\end{tabular}

Fuente: elaboración propia.

Como se puede comprobar en la tablas 4.1 y 4.2, se han seleccionado las palabras clave más representativas a lo largo de las dos entrevistas, pudiéndose comprobar de esta forma cuál ha sido el hilo seguido durante éstas y en qué aspectos se ha profundizado en mayor medida. Por otro lado, también se muestran en ambas tablas aquellas palabras indigenas o conceptos que el entrevistador desconocía antes de la realización de la entrevista y que le han llamado la atención por su importancia para la investigación. En la entrevista E1, todas ellas se encuentran relacionadas con el marketing y la satisfacción del turista y por el contrario, en la entrevista E2 solamente se ha detectado un término desconocido para el entrevistador. Respecto a las palabras más repetidas, se ha realizado una división de cada concepto repetido según la familia de códigos a la que correspondiese en el análisis realizado con Atlas.ti, existiendo también una serie de palabras de carácter general que no han sido adscritas a ninguna familia de códigos concreta.

En las imágenes 4.1 y 4.2 que contienen las nubes de palabras más repetidas en sendas entrevistas, se puede comprobar de una forma más visual que aquellas palabras que disponen de un mayor tamaño son las que se han repetido más veces a lo largo de la entrevista y por tanto, han obtenido una mayor importancia en ésta.

Imágenes 4.1 y 4.2: Nube de palabras más repetidas de la entrevista a los expertos E1 (izquierda) y E2 (derecha).
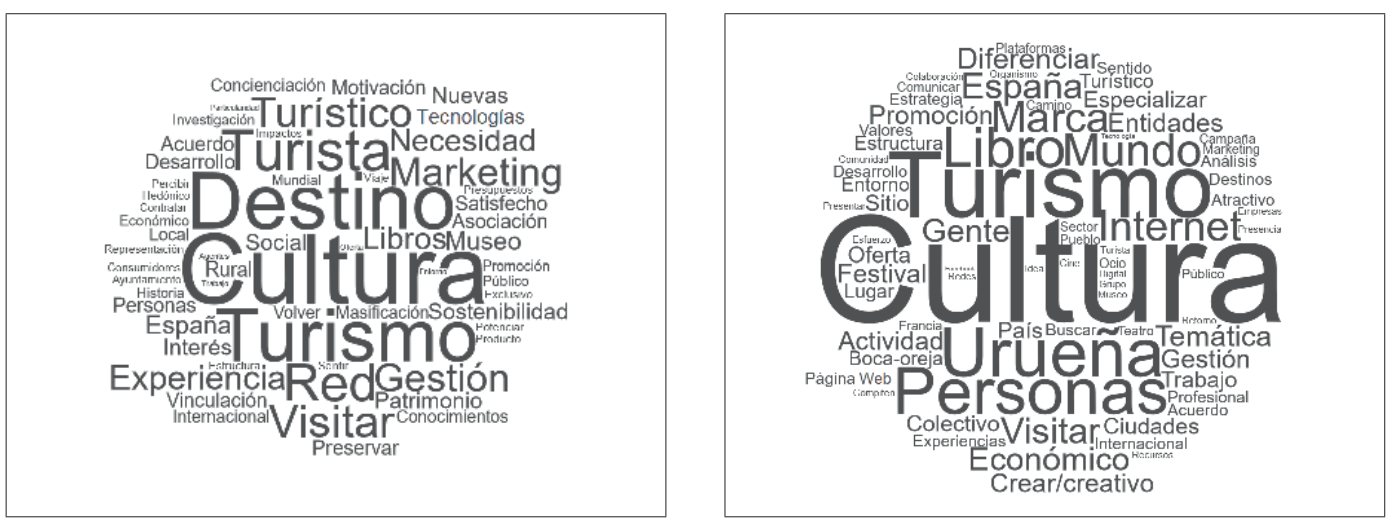

Fuente: elaboración propia. 


\subsection{Resultados del Análisis de Contenidos para la Entrevista E1}

A continuación es necesario detallar los resultados del análisis mantenido en la entrevista y llevado a cabo a través de Atlas.ti. Para ello, se presentan los resultados interpretados en función de los cuatro grupos temáticos de palabras mostrados anteriormente, los cuales, según lo establecido en el análisis, serían considerados como causas generales que explicarían el efecto que el experto entrevistado querría obtener de la aplicación de éstas, es decir, que la atención y satisfacción de las necesidades de los turistas culturales deben completarse a través de la realización de diferentes acciones vinculadas a la gestión turística, el marketing, y la sostenibilidad, teniendo en cuenta el comportamiento de los propios turistas.

De esta forma, en primer lugar, se expresan diferentes aspectos acerca de la gestión del turismo cultural por parte del experto E1, comenzando por aquellos que se refieren a la evolución del turismo cultural en España. En este sentido, considera que esta tipología turística tiene en realidad un desarrollo reciente y complicado en muchos aspectos, afirmando que la evolución del turismo cultural ha sido muy lenta y concentrada en las últimas décadas. La clave para que un destino de turismo cultural prosiga desarrollándose de forma adecuada es, según el experto, la consecución del objetivo de satisfacción de las necesidades de los turistas que lo visitan, algo que se está consiguiendo en España a través de la implantación y adaptación hacia nuevas tendencias como el uso de nuevas tecnologías.

En relación con las transformaciones acontecidas en la gestión del turismo cultural, el E1 otorga un papel importante a la formación de gestores eminentemente turísticos, expresando la necesidad en la profesionalización del personal especializado en turismo, ya que considera que en el turismo cultural español ésta ha sido escasa y muy ligada a profesionales de la cultura, el arte o la historia, dejándose de lado disciplinas como el marketing, produciendo desequilibrios que se está corrigiendo de manera desigual. Por tanto, el experto cree necesaria la incorporación de gestores turísticos con formación multidisciplinar que sean capaces de diseñar e implementar estrategias a nivel general en los destinos.

Asimismo, también aparece reflejada en diferentes ocasiones durante la entrevista la implicación de los diferentes agentes que influyen sobre el turismo cultural en un lugar determinado, manifestando el experto su conformidad respecto a la participación y colaboración de éstos en un destino concreto y mostrando especial interés en la necesidad de otorgar a la población local un papel destacado en la toma de decisiones.

Vinculadas a la gestión turística de los destinos culturales se encuentran también todas aquellas afirmaciones realizadas por el E1 acerca del desarrollo turístico de los entornos rurales y el diseño de éstos, considerando que los gestores turísticos deben planificar los desarrollos en función de atractivos principales que a su vez sean complementados por otros recursos y productos turísticos del entorno, con el objetivo de establecer un desarrollo mucho más amplio que abarque un mayor número de posibilidades para la actividad turística.

En relación a la causa general vinculada a la sostenibilidad y los impactos producidos por el desarrollo turístico, el E1 considera que los impactos socioculturales negativos que produce el turismo cultural no se han solventado, manifestando su preocupación por aquellas situaciones en las que la población autóctona se ve desplazada por el crecimiento turístico o bien no se le tiene en cuenta como una parte relevante del destino. Por otro lado, el experto también considera muy importante atender a la sostenibilidad económica de los destinos culturales y sus productos incorporados, de ahí que proponga un seguimiento a las cuentas turísticas de los destinos turísticos, atendiendo a las formas de financiación posibles para la consecución de los objetivos marcados.

Por último, respecto a los impactos que el turismo pueda producir en el medio ambiente en los destinos culturales, el experto considera que a modo general se está consiguiendo que se tenga en cuenta todo aquello que tiene que ver con el respeto al entorno. Asimismo, considera que la buena gestión medioambiental de los destinos culturales puede traer notables efectos positivos para los turistas, ya que el disfrute de la estancia será mucho mayor en un entorno cuidado y no masificado, teniendo en cuenta también que se deberá velar para que los propios turistas respeten el propio entorno.

En cuanto a los aspectos que el experto ha tenido en cuenta sobre la causa general vinculada al marketing y el turismo cultural, se han detectado en la entrevista dos líneas generales de actuación en clave de marketing del turismo cultural para la satisfacción de las necesidades de los propios turistas: la creación e impulso de estrategias de asociación entre destinos y/o productos en forma de red que permita crear fortalezas a nivel general, y el empleo de nuevas tecnologías con el objetivo de que el turista diseñe sus propios productos. Respecto al primer enfoque, el E1 considera que los beneficios pueden producirse a través de la realización conjunta de estrategias de posicionamiento o de promoción, a modo de ejemplo. De lo que se trataría, según se deduce de la entrevista, es de fortalecer aquellos aspectos en los que los destinos no disponen de suficientes recursos para emprender acciones concretas 
por sí solos. En cuanto al segundo enfoque, el experto considera que a través de las nuevas tecnologías se pueden implantar estrategias que permitan mejorar estas plataformas de colaboración entre destinos turísticos, con el objetivo de que el propio turista sea partícipe en el diseño de su viaje.

Debe mencionarse que los resultados obtenidos en la anterior causa general se encuentran muy relacionados con las acciones a favor de estudiar y orientar el comportamiento del turista cultural en relación a su efecto en la satisfacción de las necesidades de éstos. De esta forma, el E1 considera que en la actualidad las necesidades de los turistas culturales van mucho más allá de la propia experiencia durante el viaje, ya que cada vez optan más por compartir impresiones e informarse sobre el destino a través de las nuevas tecnologías. Igualmente, el experto valora la transformación del turista cultural en el sentido de una mayor concienciación y responsabilidad a la hora de tratar los temas vinculados al medio ambiente y al Patrimonio Cultural, teniendo la necesidad de preservarlo para las generaciones futuras. Por otro lado, el experto considera que el comportamiento del turista cultural ha evolucionado también desde la búsqueda de conocimiento hacia una serie de motivaciones y necesidades más profundas y adaptadas a sus propios gustos.

Cabe destacar también la importancia que se le otorga en la entrevista a la lealtad de un turista hacia un destino o producto, ya que es un comportamiento que permite consolidar la posición del destino y al mismo tiempo puede hacer cada vez más satisfactoria la experiencia del turista. De esta forma, el E1 considera que si un turista detecta elementos que aumentan su satisfacción durante la estancia, es muy probable que repita su visita en otra ocasión. Así pues, el experto observa como las redes pueden servir como elemento que potencie la lealtad de los turistas hacia una serie de destinos concretos y similares a los ya visitados, pero con experiencias ligeramente distintas que pueden llegar a constituir una itinerario a seguir. Así, y tras plantear al E1 el caso específico de una posible red turística de Villas del Libro, éste examina la complejidad del carácter internacional de dicha red de destinos, por lo que apostaría por cuidar más aún si cabe los aspectos de los que dispone el marketing para hacer posible que los turistas culturales, y más concretamente, los turistas literarios, sean leales a la red y posean la necesidad de recorrer los diferentes puntos pertenecientes a ésta. De esta forma, el E1 considera que la experiencia que debe vivir el turista en un destino perteneciente a una red internacional, tiene que ser muy importante y marcar notablemente al turista para que se decida a viajar por otros países o regiones en busca de los destinos similares.

\subsection{Resultados del Análisis de Contenidos para la Entrevista E2}

Por su parte, del análisis sobre lo comentado por el experto E2 se han extraído los resultados en función de tres grandes causas correspondientes a los grupos de palabras mostrados en la tabla 4.2 que vendrían a explicar el efecto detectado, que en este caso sería el desarrollo de la internacionalización de un destino cultural a través de las nuevas tecnologías y las estrategias de marketing. Al igual que en la anterior entrevista, se exponen los resultados de la interpretación de la entrevista en Atlas.ti partiendo de la causa general de mayor tamaño, la que respecta a la gestión turística.

En un primer lugar, el experto expuso distintos motivos por los que consideraba que la gestión del turismo cultural en España no se estaba realizando de forma adecuada y conforme a lo que él considera que es el ámbito de futuro en este aspecto, la aplicación de las nuevas tecnologías. El experto denota una falta de creatividad y de aspectos diferenciadores en los destinos españoles frente a destinos culturales de otros países. Además, expone que hasta fechas recientes no se había producido el salto definitivo a las nuevas tecnologías por parte del turismo cultural, el cual había quedado estancado en una serie de estrategias de promoción poco innovadoras que no resultaban suficientes para la dinamización de los destinos culturales.

Así pues, el experto E2 llega a exponer la necesidad de adaptar el turismo cultural a las nuevas demandas exigidas por los turistas, entre las que se encuentran la necesidad de incluir actividades culturales a los productos y/o destinos turísticos no culturales, con el fin de iniciarles en la práctica del turismo cultural y de conseguir un número importante de turistas que realicen distintas prácticas durante su viaje, esto es, diversificar. Por tanto, debe prestarse más atención a los turistas no culturales, ya que a éstos es necesario incluirles actividades que también son consideradas como turismo cultural y que pueden complementar a la motivación principal que no es cultural, ampliando así el concepto de destino. El experto cita el Hay Festival de Segovia como uno de los ejemplos a seguir en este aspecto, ya que se ha producido una diversificación de la oferta cultural en torno a este festival que permite atraer a diferentes personas con diferentes intereses principales, culturales y no culturales. 
Por otro lado, para destinos culturales de carácter rural el E2 propone su especialización en una temática turística principal, al hilo de lo implantado en la Villa del Libro de Urueña. Sin embargo, éste considera que una excesiva especialización puede tener un efecto contrario, ya que se desvincularía del destino a turistas que no se encuentran interesados en la temática sobre la que gira exclusivamente el desarrollo turístico. En este sentido, y para evitar la situación mencionada, el experto se posiciona a favor de emprender una estrategia mixta de especialización-diversificación, en la que el destino turístico se especializa en una temática principal, pero al mismo tiempo permite la realización de otras actividades culturales distintas que pueden atraer a turistas con diferentes motivaciones.

Vinculado a la gestión de los destinos culturales, otro aspecto que considera el experto como elemento clave en relación con la gestión de los destinos culturales es la existencia de personal vinculado y con conocimientos en materia de turismo cultural, siendo necesario disponer de un gestor de destino especializado en turismo que cuente con un equipo con profesionales de esta disciplina y otras complementarias.

Por último, para terminar lo referido a la gestión del turismo cultural, se mencionan en la entrevista de forma breve los aspectos relacionados con la sostenibilidad en destinos turísticos, tomando el experto una posición pesimista en la que asegura que existe escasa sensibilidad en temas medioambientales por parte de las instituciones y empresas turísticas, la cual considera que no se va a modificar a corto plazo.

Respecto a la causa general vinculada al marketing, el experto plantea dos estrategias principales para destinos culturales de carácter rural: product placement y boca-oreja. En cuanto a la primera, el experto considera que permite aumentar el conocimiento del destino por parte de los potenciales turistas a través de la realización de eventos desarrollados por conocidas marcas en el mismo, suponiendo tanto un beneficio tanto para el destino como para las marcas en cuestión. En este sentido, dicha estrategia es planteada como soporte de financiación añadido para los destinos, pero para ello debe existir voluntad por parte de las instituciones públicas para facilitar el mecenazgo por parte de entidades privadas. El experto vuelve a poner de ejemplo el Hay Festival, ya que los organizadores del evento emplean dicha estrategia a través de marcas que no tienen por qué pertenecer al sector cultural, financiando el evento y al mismo tiempo éstas desarrollan y experimentan con sus productos, lo que puede atraer aún más la atención de los posibles visitantes o asistentes. En el caso del boca-oreja, el E2 aboga por la incitación a los turistas a difundir su experiencia a través de internet, con el objetivo de que dicha información llegue a personas cercanas a éstos y decidan viajar al destino atraídas por la satisfacción manifestada durante la visita.

Por otro lado, se pudo apreciar durante toda la entrevista que el experto le otorga la máxima importancia a combinar el uso de las nuevas tecnologías con el desarrollo turístico. En este sentido, respecto a la causa general vinculada a ello, se deduce que el experto echa en falta la apuesta del turismo cultural español por las nuevas tecnologías y el uso de internet para su desarrollo, siendo para él uno de los aspectos clave para el futuro del sector. El experto considera que se debe seguir en esta línea de implantación de nuevas tecnologías, concretamente en el fomento del uso de las redes sociales, con el objetivo de fidelizar al turista cultural y a su vez atraer a un nuevo público potencialmente interesado en ello. De esta forma, el experto asegura que si un turista decide repetir su visita a un destino cultural es porque ha quedado satisfecho, siendo principalmente las nuevas tecnologías el vehículo actual para transmitir dicha satisfacción y hacer que otras personas se muestren interesadas en ir.

Por otra parte, se planteó al experto la posibilidad de diseñar redes turísticas que agrupen destinos de turismo rural de carácter similar a lo que se podría desarrollar en las Villas del Libro, orientando éste su respuesta hacia el papel que pueden desempeñar las nuevas tecnologías en este desarrollo. Así pues, considera importante el papel de las redes sociales y otras aplicaciones que permitan difundir y hacer accesibles a los turistas los destinos de la red, según los intereses de éstos. En este sentido, el experto confirma en la entrevista su posición acerca de la clara e indiscutible presencia de estas asociaciones de destinos capaces de de atraer tanto a un público nacional como extranjero. Por último, es necesario exponer que para el experto tanto la conformación de redes internacionales de destinos, como la realización de estrategias y acciones capaces de atraer a un público internacional, son los elementos imprescindibles para el desarrollo y viabilidad de destinos culturales de reducido tamaño y de carácter rural como las Villas del Libro. En este sentido, como lo fue demostrando el experto durante toda la entrevista, dicha internacionalización debe soportarse a través del uso de las nuevas tecnologías, desarrollando de forma primordial una página web de calidad que contenga la mayor información posible para los visitantes tanto nacionales como internacionales. 


\section{Conclusiones y recomendaciones}

\subsection{Conclusiones}

En el presente artículo se ha puesto de manifiesto la necesidad de continuar apostando por la investigación en el campo del turismo cultural, dadas las constantes transformaciones que viene experimentando esta modalidad turística en las últimas décadas, especialmente en el marco de las nuevas tecnologías y las estrategias de gestión y marketing vinculadas a ellas. En este caso, la atención se ha centrado sobre los destinos rurales que han iniciado estrategias de especialización en turismo literario y más concretamente, en aquellos que han sido declarados Villas del Libro, como es el caso de la localidad vallisoletana de Urueña. De esta forma, los expertos consultados para esta investigación cualitativa han coincidido en manifestar la tardanza en la adaptación del turismo cultural español a las nuevas tendencias seguidas en la actualidad, así como la existencia de dificultades a nivel general en materia de profesionalización turística y viabilidad económica de los desarrollos establecidos. De un modo más concreto, en la entrevista mantenida con el experto E1 se destacó la importancia de las nuevas tendencias en turismo cultural como forma de satisfacer las necesidades de los turistas actuales, más comprometidos con su entorno y conscientes culturalmente. Igualmente, el experto E1 expuso reiteradamente el papel imprescindible que tiene la población local en el aumento o disminución del grado de satisfacción de los visitantes con el propio destino, y la escasa importancia que se le suele otorgar a ello en muchos desarrollos, llegándose a producir situaciones desfavorables para todos los colectivos. Desde una perspectiva distinta, el experto E2 destaca en la entrevista la necesidad de emprender en los destinos culturales rurales una estrategia combinada que sea capaz de diversificar las actividades y las clases de turistas y al mismo tiempo especializarse en una determinada tipología turística como la literaria, con el objetivo de afrontar un desarrollo adecuado.

En cuanto a las estrategias de marketing que cada entrevistado le ha otorgado más importancia para destinos como las Villas del Libro, el experto E1 considera imprescindible la asociación entre destinos similares para obtener sinergias de dicha vinculación, así como el empleo de las nuevas tecnologías para favorecer la participación del turista en el diseño de productos. Por parte del experto E2, la importancia del empleo de estrategias de product placement mediante asociaciones con marcas reconocidas al mismo tiempo que se favorece el desarrollo de un boca-oreja digital, es vital para el desarrollo de este tipo de destinos, poniendo como ejemplo lo acontecido en el Hay Festival segoviano.

Por último, mencionar que las principales discrepancias entre ambos expertos surgieron en lo vinculado a la sostenibilidad y los impactos medioambientales. El experto E1 le otorga notable importancia a dichos aspectos, exponiendo que los turistas se muestran cada vez más concienciados en relación al medio ambiente y la sostenibilidad, mientras que el experto E2 detalla estos elementos de forma breve y a través de diferentes afirmaciones repartidas por toda la entrevista. En este sentido, en materia medioambiental, la posición de la que parte el experto E2 no es desde la concienciación cada vez mayor de los turistas, sino de la escasa sensibilidad existente en temas medioambientales por parte de las instituciones y empresas turísticas.

\subsection{Recomendaciones}

Por último, las recomendaciones de esta investigación para este tipo de destinos basadas en las respuestas de ambos expertos, se sitúan en destacar la necesidad de formar gestores turísticos profesionales y multidisciplinares, así como en el empleo de las nuevas tecnologías y herramientas aplicadas al turismo con el objetivo de satisfacer las necesidades de los turistas, prestando especial atención a aquellos turistas no culturales y así poder ampliar tanto las tipologías de turistas que visiten los destinos, como incrementar el tamaño de los destinos mediante la inclusión de otros atractivos y actividades que permitan mejorar la dinamización económica en su entorno. De forma similar, debe resaltarse que el éxito y desarrollo futuro de los destinos culturales de carácter rural, entre los que se incluyen las Villas del Libro, debe basarse principalmente en su agrupación en forma de red a través del empleo de estrategias vinculadas a las nuevas tecnologías. En este sentido, debe matizarse que para el caso de destinos interconectados a nivel internacional, la lealtad del turista hacia esta red de destinos debe ser muy intensa y como consecuencia de una experiencia turística muy importante para permitir dicho desplazamiento internacional. De forma complementaria, se recomienda una mayor atención a la necesidad de atraer por parte de estas agrupaciones de destinos un importante número de turistas internacionales a través de herramientas web que permitan la personalización del viaje y descubrir todos los elementos del destino a través de ellas. 


\section{Bibliografia}

Bedate Centeno, A. M., Sanz Lara, J. A. y Herrero Prieto, L. C.

2001. Turismo cultural y patrimonio histórico: aplicación multivariante al estudio de la demanda.

Estudios Turísticos, 150: 113-132.

Babbie, E.

2000. Fundamentos de la investigación social. México: International Thomson Editores.

Butler, R.

2002. "Turismo literário". In Jafari (Ed.), Enciclopedia del Turismo. Madrid: Síntesis.

Camprubí, R. y Coromina, L.

2016. Content analysis in tourism research. Tourism Management Perspectives, 18: 134-140.

Cohen, E.

1988. Authenticity and Commoditization in Tourism. Annals of Tourism Research, 15 (3). 371-386.

ECTARC

1989. Contribution to the Drafting of a Charter for Cultural Tourism. En: Richards, G. (ed.) (1996).

Cultural Tourism in Europe. Wallingford: CAB International.

Fawcett, C. y Cormack, P.

2001. Guarding Authenticity at Literary Tourism Sites. Annals of Tourism Research, 28 (3): 686-704.

Garrod, B. y Fyall, A.

2000. Managing Heritage Tourism. Annals of Tourism Research, 27 3): 682-708.

Herbert, D.

1996. Artistic and literary places in France as tourist attractions. Tourism Management, 17 (2): 77-85.

Herbert, D.

2001. Literary places, Tourism and the Heritage experience. Annals of Tourism Research, 28 (2): 312-333.

Hernández Sampieri, R.

2007. Fundamentos de metodología de la investigación. Madrid: McGraw Hill.

López Noguero, F.

2002. El análisis de contenido como método de investigación. XXI, Revista de Educación, 4: 167-169.

Magadán Díaz, M. y Rivas García, J.

2010. El libro como patrimonio cultural y atractor turístico. En: Investigaciones, métodos y análisis del turismo, (pp.68-100). Oviedo: Septem Ediciones.

Manrique Martínez, J. Urueña

2006a. de burgo feudal a Villa del Libro: una acción íntegra de aprovechamiento patrimonial en Valladolid.

Boletín Arkeolan, 14: 421-442.

Manrique Martínez, J.

2006b. La Villa del Libro. Una acción integral de cultura y turismo. Hibris: Revista de bibliofilia, 35: 54-57.

MacCannell, D.

1999. The Tourist: A New Theory of the Leisure Class. Londres: University of California Press.

McKercher, B. y Du Cros, H.

2002. Cultural Tourism: The Partnership Between Tourism and Cultural Heritage Management. Nueva

York: The Haworth Press.

McShane, $\mathrm{P}$.

2002. To further Australia's understanding and involvement in the international booktown movement through a program of visits and interviews. Canberra: The Winston Churchill Memorial Trust of Australia.

OMT-UNWTO

1985. The State's Role in Protecting and Promoting Culture as a Factor of Tourism Development and the

Proper Use and Exploitation of the National Cultural Heritage of Sites and Monuments for Tourism.

Madrid: Organización Mundial del Turismo.

Prat Forga, J. M. y Cànoves Valiente, G.

2016. La revalorización turística del patrimonio judío en España. Sus barrios y su vino. Investigaciones turisticas, 11: 52-71.

Recuero Virto, N., Blasco López, F. y García de Madariaga Miranda, J.

2016. Marketing del turismo cultural. Madrid: ESIC. 
Reguera San José, A. I.

2014. Urueña, Villa del Libro. Aproximación a la imagen de un destino turístico (Trabajo Fin de Grado).

Universidad de Valladolid.

Richards, G. (Ed.)

1996. Cultural Tourism in Europe. Wallingford: CAB International.

Richards, G. (Ed.)

2001. Cultural Attractions and European Tourism. Nueva York: CABI Publishing.

Robinson, M.

2003. Between and Beyond the Pages: Literature-Tourism Relationships. En: Literature and Tourism:

Essays in the Reading and Writing of Tourism, (pp.39-79). Londres: Thomson.

Robinson, M. y Andersen, H. C.

2003. Reading Between the Lines: Literature and the Creation of Touristic Spaces. En: Literature and

Tourism: Essays in the Reading and Writing of Tourism, (pp.1-38). Londres: Thomson.

Sancho Pérez, A. (Dir.)

2001. Apuntes de Metodología de la Investigación en Turismo. Madrid: Organización Mundial del Turismo. Seaton, A.

1996a. Hay on Wye, the mouse that roared: book towns and rural tourism. Tourism Management, 17

(5): 379-382.

Seaton, A.

1996b. Book towns and rural tourism development: Hay on Wye 1961-1996. Glasgow: Scottish Enterprise and the Scottish Tourism Research Unit, University of Strathclyde.

Seaton, A.

1996c. Book towns and rural tourism development, Part II: the New European Book Towns. Glasgow:

Scottish Enterprise and the Scottish Tourism Research Unit, University of Strathclyde.

Seaton, A.

1999. Book towns as tourism developments in peripheral areas. The International Journal of Tourism

Research, 1: 389-399.

Smith, M.K.

2003. Issues in Cultural Tourism Studies. Londres: Routledge.

Squire, S. J.

1994. The Cultural Values of Literary Tourism. Annals of Tourism Research, 21 (1): 103-120.

Squire, S. J.

1996. Literary tourism and Sustainable tourism: promoting 'Anne of Green Gables' in Prince Edward

Island. Journal of Sustainable Tourism, 4 (3): 119-129.

Swarbrooke, J.

1996. Towards a sustainable future for cultural tourism: a European perspective. En: M. Robinson et al.

(Ed.), Tourism and Culture: Managing Cultural Resources for the Tourist, (pp.227-255). Newcastle:

The Centre for Travel and Tourism (University of Northumbria), Business Education Publisher.

Veal, A. J.

2006. Research methods for leisure and tourism: a practical guide. Harlow: Prentice Hall.

Vera Rebollo, J. F. (coord.)

2011. López Palomeque, F., Marchena Gómez, M. y Antón Clavé, S. Análisis territorial del turismo y planificación de destinos turísticos. Valencia: Tirant lo Blanch.

Recibido:

$28 / 09 / 2017$

Reenviado:

$27 / 03 / 2018$

Aceptado:

$02 / 04 / 2018$

Sometido a evaluación por pares anónimos 